\title{
MANAGEMENT \& CARING FOR PATIENTS OF COPD WITH COVID-19: A CURRENT PERSPECTIVE
}

\author{
SM AA MAMUN ${ }^{1}$, QUAZI TARIKUL ISLAM ${ }^{2}$, SANA ULLAH SARKER ${ }^{3}$, SONIA MANNAN ${ }^{4}$
}

\begin{abstract}
:
Currently passing pandemic of SARS COVE-2, that started on December 2019 has been taken nearly 2.8 million lives till April 2021, with a highest mortality among males, older individuals and patients with comorbidities. COPD patients are included in shielding strategies due to their susceptibilityto virusinduced exacerbations, compromised pulmonary function and highprevalence of associated comorbidities. Based on our existing knowledge, Experience of last one year \&Metaanalysis of different study report, thisreview has taken the initiative to find the answer of few key question: FirstlyIs the Covid19 infection causing AECOPD like any other viralinfection. Secondly, do systemic corticosteroids offer protection againstCOVID-19 with COPD ? And, finally, what is the evidence regarding use ofMDI or nebulization $\&$ NIV as standard treatment. This up-to-date review will make scope for some of the key issues which have significant impact on the long-term outlook for COPD patients in thecontext of COVID-19.
\end{abstract}

Key words: COVID-19, COPD, NIV

Received: 17.4.2021

Accepted: 28.5.2021

DOI: https://doi.org/10.3329/bjm.v32i2.53804

Citation: Mamun SMAA, Islam QT, Sarker SU, Mannan S. Management \& Caring for Patients of COPD with COVID-19: A Current Perspective. Bangladesh J Medicine 2021; 32: 165-169.

\section{Introduction:}

Chronic obstructive pulmonary disease (COPD) represents largest population of patients ${ }^{1}$ in the world and is the fourth leading cause of death in the United States. ${ }^{2}$ Like other co morbidities, COPD increase the risk for severity of COVID-19, ${ }^{3,4}$ and a better understanding of the therapeutic implications for COVID-19 in the COPD population is needed. We know that SARS-CoV-2 is currently passing as a pandemic of COVID-19, with more than 130 million confirmed cases around the globe identified as of March 2021. During these extraordinary times, caring for patients with COVID-19 and underlying COPD poses particular challenges. Though COVID-19 infection of COPD patient might not be a typical AECOPD, physicians should take the underlying COPD into consideration when treating COVID-19 in COPD. ${ }^{5}$ While previous coronaviruses MERS-CoV, SARS-CoV have been associated with COPD exacerbations ${ }^{6}$ and COVID-19 have not yet documented to cause COPD exacerbations. If a patient presents with a COPD exacerbation with concurrent COVID-19 infection, we recommend standard-of-care treatment along with corticosteroids. ${ }^{7}$ Comorbid condition like diabetes has also been associated with increased risk related to COVID $-19^{8}$ and glycemic control may be an additional challengewhen using corticosteroids in this population. Although, diagnosing COVID-19 in a patient with COPD does not preclude a concomitant AECOPD and the need for urgent treatment for this but treating patients with moderate to severe COPD may necessitate using bronchodilators, NIV and the frequent need for antibiotics. ${ }^{9}$ Concerns have been raised as to whether and how these therapies should be offered to patients with COPD during the pandemic.

Should COVID-19 infection be considered a COP Dexacerbation? A controversy !!

Like seasonal flu, different coronaviruses are recognised seasonal causesof acute exacerbations of COPD (AECOPD). There remains controversy asto whether COVID-19 in a patient with underlying COPD should beconsidered a COPD exacerbation. This stems from our current definition ofan exacerbation being a

1. Senior Consultant \& Co-ordinator of Respiratory Medicine, Square Hospitals, Dhaka, Bangladesh

2. Professor of Medicine, Popular Medical College, Dhaka, Bangladesh

3. Specialist, Respiratory Medicine, Square Hospitals, Dhaka, Bangladesh

4. Registrar, Respiratory Medicine, University Hospital Coventry \& Warwickshire, UK

Corresponding address: Dr. SM AA Mamun, Senior Consultant \& Co-ordinator of Respiratory Medicine, Square Hospitals, Dhaka, Bangladesh. E-mail: mamundr69@gmail.com 
clinical diagnosis based on a change in symptoms needing a change in treatment. ${ }^{5}$ Thus, a patient with COVID-19 and COPDpresenting with increased cough and breathlessness requiring treatmentwould fulfill the current definition of exacerbation. However, it is clear fromimaging and postmortem studies that the pathology of a typical AECOPD isvery different from the viral pneumonia typical of COVID-19. ${ }^{8}$ Thus, conceptually, COVID-19 in a patient with COPD is likely a very different pathphysiological process.

\section{Rationale of using Antibiotics:}

Outside the context of COVID-19, not all AECOPDs should be treated with antibiotic ${ }^{5}$ and current guidelines suggest reserving antibiotics for AECOPDs that require hospitalization or ventilatory support. ${ }^{10}$ Overall, bacterial co-infections are uncommon in COVID-19: Recent meta-analysis has shown that only $8 \%$ of patients had a bacterial/fungal coinfection. ${ }^{11}$ The risk of coinfections increases with the severity of COVID-19: A cohort study on risk factors for in-hospital death from COVID-19 found that 50\% ofnon-survivors experienced secondary infections and that ventilator associated pneumonia was seen in $31 \% .{ }^{25}$ Since it may be difficult todistinguish SARS-CoV-2 infections from a bacterial pneumonia andbecause patients with COPD are at risk for bacterial (super)infections, wesuggest treating hospitalized patients with COPD and COVID19 andrespiratory symptoms with broad-spectrum antibiotics, guided by local/national guidelines for treating pneumonia. This is in line with the current WHO treatment guideline for severe COVID-19.26 Microbiological analysis, such as sputum culture, should be performed on admission and it may then be reasonable to stop antibiotics in the absence of a confection.

\section{Systemic corticosteroids:}

It is recognised that not all AECOPDs need to be treated with systemic corticosteroids. ${ }^{5}$ Eosinophil-based steroid treatment has been advocated for both stable COPD and AECOPD; However, the use of this strategy in patients with COPD and COVID-19 has not been tested. Until recently, the efficacy of corticosteroids in general for treating COVID-19 was inconclusive, though a cohort study suggested steroids might improve clinical outcome in patients with COVID-19. ${ }^{12}$ Recent, preliminary results from the Randomized Evaluation of COVID-19 Therapy (RECOVERY) trial have shown that dexamethasone improves mortality in patients with COVID-19 requiring respiratory support. ${ }^{13}$ The WHO recommended against the use of steroids previously, but is now updating treatment guidelines to include dexamethasone or other corticosteroids. Corticosteroids are beneficial to patients with severe AECOPD, especially inpatients requiring ventilatory support, in whom steroids reduce ventilation days and NIV failure; therefore, it is reasonable to treat patients with COPD and severe COVID-19 with course of corticosteroids. The RECOVERY regimen of $6 \mathrm{mg}$ dexamethasone once daily could be used until more evidence is providedto guide treatment in patients with COPD with COVID-19.

\section{Bronchodilator nebulization \& NIV:}

Nebulization of short acting bronchodilators are frequently practiced in hospitalized patients with COPD. Information, guidance and resources to support the respiratory community during the COVID-19 pandemic, the British Thoracic Society (BTS) have published guideline on treating patients with COPD and COVID-19. ${ }^{14}$ This guideline supports the use of nebulisers, claiming there is no evidence supporting an increased risk of viral transmission and, second, that aerosols surrounding the nebuliser come from the nebuliser not from patients. ${ }^{14}$ However, the metaanalysis suggesting nebulisers do not increase viral transmission has some methodological concerns. ${ }^{15}$

The BTS guideline was also based on a methodological study showing that nebulisers predominantly produce aerosols not droplets, also used to suggest that nebulisation was safe. ${ }^{16}$ Viral transmission was not the subject of this investigation and since it remains open to debate whether droplets or aerosols can contain SARS-CoV-2, we do not think these resultsshould be used as reassurance of no risk of transmission. Alternative modes of inhalation are available, including pressurized metered-dose inhalers (pMDI) used with a spacer \& Aerochamber. In AECOPDpMDIs are not inferior to nebulisers. ${ }^{17}$ Long-acting dual bronchodilators may be preferred; some also have a fast onset of action, and are more effective with a longer duration of action. There are currently two long-acting pMDI combinations available which can be used with a spacer. No maximum dosing has been provided for nebulized short-acting bronchodilators and very high doses are often administered for AECOPD. We suggest doubling the maximum maintenance dose of longacting bronchodilators, reflecting the high doses of short-acting bronchodilators often used in clinical practice. Since the safety of nebulisersis controversial and given that there is a suitable alternative, we recommend bronchodilators administered by pMDI and spacer over the use of nebulizer treatment in symptomatic patients with COPD and COVID-19. Nebulised treatment should be reserved for those situations in which pMDI with spacer is not possible, such as patients with severe, life-threatening disease or those unable to use a pMDI. For healthcare workers, 
respiratory masks (FFP-3 or equivalent) and other personnel protective equipment should be used during aerosol-generating procedures such as nebulisers. ${ }^{17}$ In patients with COPD with acute (on chronic) hypercapnic respiratory failure, NIV should be considered. ${ }^{18}$ There are no data showing that HFNCis equivalent or superior to NIV . So in this population we ecommendusing NIV first line. If NIV is used, a mask with no leak and dual limbbreathing circuits should be used to prevent viral contamination. Transmission of virus can be reduced by using a nonvented mask with the exhaled air passing through a bacterial/viral filter before entering the room. ${ }^{15,17}$ Second, an expiration system with an active valve can be usedand the oxygen supply can be connected close to the mask, so that ahigher $\mathrm{FiO}_{2}$ can be reached. ${ }^{21}$ Before starting NIV, the patient's willingnessto undergo invasive mechanical ventilation (IMV), if NIV fails, should be discussed.

\section{Use Of HFNC \& IMV:}

Patients with hypoxaemic COPD and COVID-19 should be given controlled oxygen therapy as the first step. ${ }^{20}$ If hypoxaemia is insufficiently controlled with maximum oxygen supplementation, high-flow nasal cannula (HFNC) or CPAP with high oxygen flow should be considered. HFNC has recently been suggested as a management option in patients with COVID- 19 with acute hypoxaemic respiratory failure ${ }^{20}$ Reduction of hypercapnia and work of breathing might be additional benefits of HFNC in patients with COPD and COVID$19 .{ }^{21}$ Problem is that, HFNC is an open system and expired air cannot be filtered. A surgical mask can be placed over the nasal cannula to limit aerosol spread. ${ }^{20}$ Besides HFNC, CPAP with a high fraction of inspired oxygen $\left(\mathrm{FiO}_{2}\right)$ might be an option to treat hypoxaemic respiratory failure. CPAP provides a certain level of positive end-expiratory pressure, which might be a useful add-on to oxygen supplementation. Furthermore, it is possible to filter expiration with CPAP and thus limit viral spread.

Invasive ventilation like IMV should be started in patients with severe hypoxaemic respiratory failure or after NIV failure[20].Specially in case of COPD, this decision should be made carefully, as it is known that inhospital mortality with IMV in AECOPD is high. ${ }^{21}$ Mortality is even higher for patients with COPD with severe COVID-19. Prolonged mechanical ventilation required in patients with COVID-19 might be particularly detrimental to the future health status of patients with COPD. Before starting IMV in patients with COPD, the risks and benefits should be explained clearly to the relatives, and patients wishes and preferences regarding this life-prolonging therapies should be considered such that known risk factors for poor outcomes of IMV in COPD ${ }^{22}$ can influence decision-making. Some home bound COPD patients living with portable home based mechanical ventilation may admitted to the hospital with COVID-19. Their ventilatory support should be continued in hospital, with precautions to limit viral spread. Home treatment, supported by tele monitoring, might be preferred. The value and goals of a hospital admission should be discussed in the low likelihood of surviving a long period of ICU admission.

How should end-of-life care be delivered in patients withCOPD during the COVID-19 pandemic?

As the patients with COPD are at an increased risk for a poor outcome after infected with COVID-19 and decision may come to forego lifesustaining treatments. It is better to discuss with family of end stage COPDpatients regarding goals and preferences for future medical treatment andcare, known as advance care planning (ACP), should have been undertakenbefore hospital admission. The challenge in the current SARS-CoV-2pandemic is addressing palliative care needs in times of crisis, at a timewhen preventing unwanted life-sustaining treatments is paramount.

Advanced care planning also includes communication about end-of-life care with health care team .Expert panel suggest timely communication about end-of-life care. ${ }^{23}$ Patients may have worries about suffocation andthe process of dying. Fear is common in patients in respiratory distress andcould be pharmacologically treated with anxiolytics, such as lorazepam. ${ }^{24}$ Morphine is the drug of choice in most of the cases to manage dyspnoea and should be start before the dying phase. ${ }^{24}$ Those patients have much suffering despite optimal symptom management, palliative sedation can be discussed with patients and their relatives. Care for relatives needs specific attention in the SARS-CoV2 pandemic: Social distancing, limiting hospital visits and the necessity of personal protective equipment imposes restriction on saying goodbye to loved ones, thereby increasing the risk for complicated grief. Therefore, bereavement care needs to be considered.

\section{Conclusions:}

The frontline physicians are at immense risk for contracting the COVID infection when caring for critically ill COPD with Covid19.Patients due to different aerosol-generation. This article provides an overview on how to manage patients with COPD and COVID-19 during the SARS-CoV-2 pandemic. Key points have been discussed. Caring for patients with COPD and COVID-19 poses special challenges for healthcare 
workers. Not only are they faced with severely ill, often elderly, patients who can deteriorate rapidly and have a poor prognosis, they are working in an environment withincreased risk of being infected themselves. The suggestions put forward in this article will provide a framework for those working in suchchallenging conditions \& to improve current clinical practice and evidencehow to treat COVID-19 effectively in patients with COPD.

\section{Conflict of Interest:}

The authors stated that there is no conflict of interest in this study.

\section{Funding:}

No specific funding was received for this study.

\section{References :}

1. Sullivan J, Pravosud V, Mannino DM, Siegel K, Choate $\mathrm{R}$, Sullivan T, National and state estimates of COPD morbidity and mortality-United States, 2014-2015. Chronic ObstrPulm Dis 2018; 5(4):324-333 https://0doi-org.libus.csd.mu.edu/10.15326/jcopdf. 5.4.2018. 0157 PMid:30723788 PMCid:PMC 6361472

2. Heron M. Deaths: Leading Causes for 2017. Natl Vital Stat Rep. 2019 Jun;68(6):1-77. PMID: 32501203.

3. Guan WJ, Ni ZY, Hu Y, et al; China Medical Treatment Expert Group for Covid-19Clinical characteristics of coronavirus disease 2019 in China. N Engl J Med 2020; Feb 28.

4. Wu C, Chen X, Cai Y, et al .Risk factors associated with acute respiratory distress syndrome and death in patients with coronavirus disease 2019 pneumonia in Wuhan, China. JAMA Intern Med 2020:e200994. https://0-doi-org.libus.csd.mu.edu/10.1001/ jamainternmed.2020.0994. PMid:32167524 PMCid: PMC7070509.

5. Global Initiative for Chronic Obstructive Lung Disease Global strategy for the diagnosis, management and prevention of chronic obstructive pulmonary disease, 2019 report. Available

6. Kurai D, Saraya T, Ishii H, Takizawa H. Virus-induced exacerbations in asthma and COPD. Front Microbiol 2013; 4:293. https://0-doi-org.libus.csd.mu.edu/ 10.3389/fmicb.2013.00293. PMid:24098299 PMCid:PMC3787546.

7. Leuppi JD, Schuetz P, Bingisser R, et al Short-term vs conventional glucocorticoid therapy in acute exacerbations of chronic obstructive pulmonary disease: the REDUCE randomized clinical trial. JAMA 2013; 309(21):2223-2231. https://0-doi-org.libus. csd.mu.edu/10.1001/jama.2013.5023. PMid: 23695200 .

8. Ackermann M, Verleden SE, Kuehnel M, et al Pulmonary vascular endothelialitis, thrombosis, and angiogenesis in Covid-19. N Engl J Med 2020;383:1208. https://0-doi-org.libus.csd.mu.edu/10.1056/ NEJMoa2015432. PMid:32437596 PMCid:PMC 7412750

9. Simons SO, Hurst JR, Miravitlles M, et al Caring for patients with COPD and COVID-19: a viewpoint to spark discussion Thorax 2020;75:1035-1039. https:/ /0-doi-org.libus.csd.mu.edu/10.1136/thoraxjnl-2020215095. PMid:32878969 PMCid:PMC7474898

10. Hopkinson NS, Molyneux A, Pink J , et al Chronic obstructive pulmonary disease: diagnosis and management: summary of updated NICE guidance. BMJ 2019;366:14486. https://0-doi-org.libus. csd.mu.edu/10.1136/bmj.14486. PMid:31358491

11. Rawson TM, Moore LSP , Zhu N, et al .Bacterial and fungal co-infection in individuals with coronavirus: a rapid review to support COVID-19 antimicrobial prescribing. ClinInfectDis 2020:ciaa530. https://0-doiorg.libus.csd.mu.edu / 10.1093 / cid / ciaa 530 PMid:32358954 PMCid:PMC7197596.

12. Wu Z, McGoogan JM, Characteristics of and important lessons from the coronavirus disease 2019 (COVID-19) outbreak in China: summary of a report of 72314 cases from the Chinese Center for Disease Control and Prevention. JAMA 2020; Feb 24. https://0-doiorg.libus.csd.mu.edu/10.1001/jama.2020.2648 PMid:32091533

13. RECOVERY Collaborative Group, Horby P, Lim WS, et al Dexamethasone in hospitalized patients with covid19 - preliminary report. N Engl J Med 2020.

14. British Thoracic Society COPD and COVID-19 for healthcare professionals. Available: V2.0 14 April 2020.

15. Tran K, Cimon K, Severn M , et al Aerosol generating procedures and risk of transmission of acute respiratory infections to healthcare workers: a systematic review. PLoS One 2012;7:e35797. https://0-doi-org.libus. csd.mu.edu/10.1371/journal. pone.0035797 PMid: 22563403. PMCid:PMC3338532

16. van Geffen WH, Douma WR, Slebos DJ, et al Bronchodilators delivered by nebuliser versus pMDI with spacer or DPI for exacerbations of COPD. Cochrane Database Syst Rev 2016;8:CD011826. https://0-doiorg.libus.csd.mu.edu/10.1002/14651858.CD 011826.pub2 PMid:27569680

17. Ferioli $\mathrm{M}$, Cisternino $\mathrm{C}$, Leo V , et al Protecting healthcare workers from SARS-CoV-2 infection: practical indications. EurRespir Rev 2020;29:200068. https: / / 0-doi-org.libus.csd.mu.edu/10.1183/ 16000617.0068-2020 PMid:32248146 PMCid:PMC 7134482

18. Osadnik CR, Tee VS, Carson-Chahhoud KV, et al Non-invasive ventilation for the management of acute hypercapnic respiratory failure due to exacerbation of 
chronic obstructive pulmonary disease. Cochrane Database Syst Rev 2017;7:CD004104. https://0-doiorg.libus.csd.mu.edu/10.1183/1393003.congress2017.OA 1770

19. Thys F, Liistro G, Dozin O, et al . Determinants of $\mathrm{Fi}, \mathrm{O} 2$ with oxygen supplementation during noninvasive two-level positive pressure ventilation. EurRespir $\mathrm{J}$ 2002;19:653-https:/ /0-doi-org.libus.csd.mu.edu/ 10.1183/09031936.02.00263102. PMid:11998994

20. Alhazzani W, Møller MH , Arabi YM, et al Surviving sepsis campaign: guidelines on the management of critically ill adults with coronavirus disease 2019 (COVID-19). Intensive Care Med 2020;46:854-87. https: / / 0-doi-org.libus.csd.mu.edu/10.1007/s00134020-06022-5. PMid:32222812 PMCid:PMC7101866.

21. de Miguel-Diez J , Jiménez-García R , HernándezBarrera $\mathrm{V}$, et al Trends in the use and outcomes of mechanical ventilation among patients hospitalized with acute exacerbations of COPD in Spain, 2001 to 2015. J Clin Med 2019;8:1621. https://0-doi-org.libus. csd.mu.edu/10.3390/jcm8101621. PMid:31590235 PMCid:PMC6832372.
22. Connors AF, Dawson NV , Thomas C, et al . Outcomes following acute exacerbation of severe chronic obstructive lung disease.The support Investigators (study to understand prognoses and preferences for outcomes and risks of treatments). Am J RespirCrit Care Med 1996;154:959-67. https:/ / 0-doi-org.libus.csd.mu. edu/10.1164/ajrccm.154.4.8887592 PMid:8887592

23. Patel K, Janssen DJA, Curtis JR Advance care planning in COPD. Respirology 2012;17:72-8. https://0-doiorg.libus.csd.mu.edu/10.1111/j.1440-1843.2011. 02087.x PMid:22008225

24. Lanken PN, Terry PB, Delisser HM , et al An official American thoracic Society clinical policy statement: palliative care for patients with respiratory diseases and critical illnesses. Am J RespirCrit Care Med 2008;177:912-27. https://0-doi-org.libus.csd.mu.edu/ 10.1164/rccm.200605-587ST PMid:18390964

25. Zhou F, Yu T, Du R, et al Clinical course and risk factors for mortality of adult inpatients with COVID-19 in Wuhan, China: a retrospective cohort study. Lancet 2020;395:1054. https://0-doi-org.libus.csd.mu.edu/ 10.1016/S0140-6736(20)30566-3

26. WHO Clinical management of COVID-19: interim guidance. World Health Organization, 2020. 